TITLE:

\title{
Short-range structures of poly(dicarbon monofluoride) (CF)n and poly(carbon monofluoride) (CF)n
}

\section{$\operatorname{AUTHOR}(\mathrm{S}):$}

Sato, Yuta; Itoh, Keiji; Hagiwara, Rika; Fukunaga, Toshiharu; Ito, Yasuhiko

\section{CITATION:}

Sato, Yuta ... [et al]. Short-range structures of poly(dicarbon monofluoride) (CF)n and poly(carbon monofluoride) (CF)n. Carbon 2004, 42(14): 2897-2903

\section{ISSUE DATE:}

2004

URL:

http://hdl.handle.net/2433/259434

\section{RIGHT:}

(c) 2004. This manuscript version is made available under the CC-BY-NC-ND 4.0 license http://creativecommons.org/licenses/by-nc-nd/4.0/.; この論文は出版社版でありません 。引用の際には出版社版をご確認ご利用ください。; This is not the published version. Please cite only the published version. 


\title{
Short-range structures of poly(dicarbon monofluoride), $\left(\mathrm{C}_{2} \mathrm{~F}\right)_{n}$,
}

\author{
and poly(carbon monofluoride), $(\mathrm{CF})_{n}$ \\ Yuta Sato $^{\mathrm{a}}$, Keiji Itoh $^{\mathrm{b}}$, Rika Hagiwara ${ }^{\mathrm{a},}$, Toshiharu Fukunaga ${ }^{\mathrm{b}}$, Yasuhiko Ito $^{\mathrm{a}}$ \\ ${ }^{a}$ Department of Fundamental Energy Science, Graduate School of Energy Science, Kyoto University, \\ Sakyo-ku, Kyoto, 606-8501, Japan \\ ${ }^{\mathrm{b}}$ Research Reactor Institute, Kyoto University, Kumatori-cho, Sennan-gun, Osaka 590-0494, Japan
}

\section{Abstract}

The short-range structures of the so-called graphite fluorides, poly(dicarbon monofluoride) $\left(\left(\mathrm{C}_{2} \mathrm{~F}\right)_{n}\right)$ and poly(carbon monofluoride) $\left((\mathrm{CF})_{n}\right)$, have been discussed, based on the neutron diffraction data. The $\mathrm{C}-\mathrm{C}$ and $\mathrm{C}-\mathrm{F}$ bond lengths in these compounds are determined to be $0.157-0.158$ and $0.136 \mathrm{~nm}$, respectively, which slightly differ from those previously evaluated and coincide with those found in polytetrafluoroethylene (PTFE). The structure models of $\left(\mathrm{C}_{2} \mathrm{~F}\right)_{n}$ (both AB-type and AA'-type) and $(\mathrm{CF})_{n}$ have been refined so as to give the best fit of the atomic pair distribution functions calculated for them $\left(G_{\text {calc }}(r)\right.$ 's) to those experimentally observed for the compounds $\left(G_{\mathrm{obs}}(r)\right.$ 's). Since the $G_{\mathrm{obs}}(r)$ of $\left(\mathrm{C}_{2} \mathrm{~F}\right)_{n}$ better fits to the $G_{\text {calc }}(r)$ 's of AB-type model rather than those for AA'-type model, the latter model is ruled out. The $a$-lattice parameter and the $\mathrm{C}-\mathrm{C}-\mathrm{C}$ bond angle in the refined structure model of $(\mathrm{CF})_{n}$ $\left(0.260-0.261 \mathrm{~nm}\right.$ and $111^{\circ}$, respectively) are slightly larger than those of $\left(\mathrm{C}_{2} \mathrm{~F}\right)_{n}$

\footnotetext{
${ }^{*}$ Corresponding author. Tel.: +81-75-753-5822; fax: +81-75-753-5906.

E-mail address: hagiwara@energy.kyoto-u.ac.jp (R. Hagiwara).
} 
$\left(0.256-0.257 \mathrm{~nm}\right.$ and $109-110^{\circ}$, respectively).

Keywords: A. Graphite, intercalation compounds; B. Intercalation; C. Neutron scattering; D. Crystal structure

\section{Introduction}

Direct fluorination of crystalline graphite by elemental fluorine at elevated temperatures above $623 \mathrm{~K}$ yields layered carbon fluorides with covalent $\mathrm{C}-\mathrm{F}$ bonds such as poly(dicarbon monofluoride) $\left(\left(\mathrm{C}_{2} \mathrm{~F}\right)_{n}\right)$ and/or poly(carbon monofluoride $)\left((\mathrm{CF})_{n}\right)$ $[1,2]$. The proposed structure models of these compounds are illustrated in Fig. 1. They have been considered to possess buckled sheets of $\mathrm{sp}^{3}$-hybridized carbon atoms with the $\mathrm{C}-\mathrm{C}-\mathrm{C}$ bond angles $(\angle \mathrm{C}-\mathrm{C}-\mathrm{C})$ of close to $109^{\circ} 28^{\prime}$ for a regular tetrahedral site [3-6]. It has been expected that every pair of the adjacent carbon sheets in $\left(\mathrm{C}_{2} \mathrm{~F}\right)_{n}$ are bound to each other by covalent $\mathrm{C}-\mathrm{C}$ bonds to form a double-decked monolayer. The AB-type and AA'-type structure models have been proposed for this compound (Fig. 1 (a) and (b)) [6]. However, these two types of the $\left(\mathrm{C}_{2} \mathrm{~F}\right)_{n}$ structures have never been distinguished from each other by the spectroscopic and diffraction analyses previously performed for this compound.

Since $\left(\mathrm{C}_{2} \mathrm{~F}\right)_{n}$ and $(\mathrm{CF})_{n}$ prepared in most cases actually possess random stacking of the fluorinated carbon layers, their XRD patterns lack the $(h k l)(l \neq 0)$ peaks, and the broad, asymmetric $(h k)$ peaks are observed instead $[7,8]$. Therefore the precise determination of the structure parameters of these compounds such as the bond lengths using the conventional Bragg diffraction patterns is quite difficult. The $a$-lattice 
parameters of $\left(\mathrm{C}_{2} \mathrm{~F}\right)_{n}$ and $(\mathrm{CF})_{n}$ based on the hexagonal unit cells, which correspond to the distance between the nearest pair of fluorine atoms attached on the same side of a carbon sheet, have been estimated at 0.251 and $0.253-0.257 \mathrm{~nm}$, respectively [5-7]. These values indicate that fluorine atoms in $\left(\mathrm{C}_{2} \mathrm{~F}\right)_{n}$ and $(\mathrm{CF})_{n}$ are closely packed and not allowed to take a typical van der Waals distance $(0.270 \mathrm{~nm})$ from each other on the carbon sheets. However, the $\mathrm{C}-\mathrm{F}$ and $\mathrm{C}-\mathrm{C}$ bond lengths $\left(r_{\mathrm{C}-\mathrm{F}}\right.$ and $\left.r_{\mathrm{C}-\mathrm{C}}\right)$ in the fluorides have been generally expected to be 0.141 and $0.153-0.154 \mathrm{~nm}$, respectively, based on the typical covalent radii of carbon and fluorine atoms (0.077 and $0.064 \mathrm{~nm}$, respectively) [5,6]. On the other hand, a computation study on $(\mathrm{CF})_{n}$ based on density functional theory has yielded in a shorter $r_{\mathrm{C}-\mathrm{F}}$ and a longer $r_{\mathrm{C}-\mathrm{C}}(0.137$ and $0.155 \mathrm{~nm}$, respectively) [9]. These bond lengths have never been further discussed up to now, while those in polytetrafluoroethylene (PTFE) consisting of $\mathrm{sp}^{3}$-hybridized carbon chains and covalent $\mathrm{C}-\mathrm{F}$ bonds have been determined to be 0.136 and $0.158 \mathrm{~nm}$ (for $r_{\mathrm{C}-\mathrm{F}}$ and $r_{\mathrm{C}-\mathrm{C}}$, respectively) based on neutron diffraction experiments [10]. In the present study, the short-range structures of $\left(\mathrm{C}_{2} \mathrm{~F}\right)_{n}$ and $(\mathrm{CF})_{n}$ were discussed, based on their radial distribution functions $(R D F(r)$ 's) and atomic pair distribution functions $(G(r)$ 's) derived from neutron diffraction data.

\section{Experimental}

\subsection{Preparation of $\left(C_{2} F\right)_{n}$ and $(C F)_{n}$}

Graphite powder (Union Carbide, SP-1 grade, purity $99.4 \%$, average particle 
diameter $\left.1 \times 10^{2} \mu \mathrm{m}\right)$ was fluorinated by elemental fluorine $(0.10 \mathrm{MPa}$; Daikin Industries, purity $99.7 \%$ ) in a nickel reactor tube at 673 or $873 \mathrm{~K}$ in order to obtain $\left(\mathrm{C}_{2} \mathrm{~F}\right)_{n}$ (sample F-1) or $(\mathrm{CF})_{n}$ (sample F-2), respectively. The $(\mathrm{CF})_{n}$ sample supplied by Daikin Industries (average particle diameter $1 \mu \mathrm{m}$; hereafter denoted by F-3), PTFE powder (Aldrich, average grain size $1 \mu \mathrm{m}$ ) and the original graphite powder were also analyzed by neutron diffraction experiments without further treatment.

\subsection{Analyses}

Elemental analyses of carbon and fluorine were performed at the Center for Organic Elemental Microanalysis of Kyoto University. XRD patterns of the powder samples charged in glass sample holders $(0.5 \mathrm{~mm}$ thick $)$ were obtained by means of MultiFlex (Rigaku) with $\mathrm{Cu} K \alpha$ radiation. The average crystallite size $(L)$ was estimated using Scherrer's equation (1);

$$
L=\frac{K \lambda}{B \cos \theta}
$$

where $K, \lambda, B, \theta$ denote the Scherrer constant, the wavelength of $\mathrm{Cu} K \alpha$ beam, the corrected half width of a diffraction peak and the Bragg angle, respectively. A $K$ value of 0.9 was used for the (001) reflection while that of 1.84 was used for the (10) reflection from the two-dimensional lattice [11].

Neutron diffraction measurements were carried out in the High Intensity Total 
Scattering Spectrometer (HIT-II) installed at the pulsed neutron source in the High Energy Accelerator Research Organization (KEK, Tsukuba, Japan). Each powder sample was put in a vanadium tube cell with an inner diameter of $8.0 \mathrm{~mm}$ and a wall thickness of $0.025 \mathrm{~mm}$. Corrections of the background, absorption [12] and the multiple scattering effects [13] were made on the experimentally observed scattering data. The structure factor in the Faber-Ziman definition, $S(Q)(Q=4 \pi \sin \theta / \lambda)$ [14], is derived from the corrected scattering intensity, $I(Q)$.

$S(Q)=\frac{I(Q)-\left\{\left\langle b^{2}\right\rangle-\langle b\rangle^{2}\right\}}{\langle b\rangle^{2}}$, where $\left\langle b^{2}\right\rangle=\sum_{i} c_{i} b_{i}{ }^{2},\langle b\rangle=\sum_{i} c_{i} b_{i}$

The $c_{i}$ and $b_{i}$ represent the concentration and the neutron coherent scattering length of the component atoms $i(i=\mathrm{C}$ or F), respectively. $R D F(r)$ and $G(r)$ are derived from the Fourier transformation of $S(Q)$.

$$
\begin{aligned}
& R D F(r)=4 \pi r^{2} \rho+\frac{2 r}{\pi} \int_{0}^{Q_{\max }} Q(S(Q)-1) \sin (Q r) d Q \\
& G(r)=\frac{2}{\pi} \int_{0}^{Q_{\max }} Q(S(Q)-1) \sin (Q r) d Q
\end{aligned}
$$

where $\rho$ represents the average number density of atoms. The $S(Q)$ and the $R D F(r)$ are also written as the weighted sum of the partial structure factors, $S_{i-j}(Q)$, and that of the partial radial distribution functions, $R D F_{i-j}(r)$, respectively $(i-j=\mathrm{C}-\mathrm{C}, \mathrm{C}-\mathrm{F}, \mathrm{F}-\mathrm{F})$. 
$S(Q)=w_{i-j} \sum S_{i-j}(Q)$

$R D F(r)=w_{i-j} \sum R D F_{i-j}(r)$

where the $w_{i-j}$ represents the weighting factor defined by Eq. (7).

$w_{i-j}=\frac{c_{i} c_{j} b_{i} b_{j}}{\langle b\rangle^{2}}$.

The nearest neighbor coordination number of atoms $j$ around an atom $i\left(C N_{i-j}\right)$ is derived from the peak area $\left(A_{i-j}\right)$ corresponding to the correlation of the nearest $i-j$ pair in the $R D F_{i-j}(r)$ according to Eq. (8).

$$
C N_{i-j}=\frac{c_{j} A_{i-j}}{w_{i-j}} .
$$

Calculation of $G(r)$ 's for the proposed structural models of $\left(\mathrm{C}_{2} \mathrm{~F}\right)_{n}$ and $(\mathrm{CF})_{n}$ was performed by the PDFFIT software [15] installed on a PC. The degree of fit of $G(r)$ calculated $\left(G_{\text {calc }}(r)\right)$ to that experimentally observed $\left(G_{\text {obs }}(r)\right)$ was evaluated using the $R$ value given by Eq. (9).

$R=\left(\frac{\sum_{i}\left(G_{\mathrm{obs}}\left(r_{i}\right)-G_{\mathrm{calc}}\left(r_{i}\right)\right)^{2}}{\sum_{i}\left(G_{\mathrm{obs}}\left(r_{i}\right)\right)^{2}}\right)^{1 / 2}$ 
Structure models were refined so as to yield the best fit of $G_{\text {calc }}(r)$ to $G_{\text {obs }}(r)$ which gives the smallest $R$ values.

\section{Results and discussion}

3.1 $C-F$ and $C-C$ bond lengths in $(C F)_{n}$ and $\left(C_{2} F\right)_{n}$

Figure 2 shows the XRD patterns of the layered carbon fluorides F-1, F-2 and F-3. The absence of the $(h k l)(l \neq 0)$ diffraction peaks and the asymmetric profiles of the ( $h k$ ) peaks in these patterns are typical of the structures with random layer stacking. The structure parameters such as interlayer distances $\left(I_{c}\right)$, the $a$-lattice parameters, the average crystallite sizes along the $c$ - and $a$-axes ( $L_{c}$ and $L_{a}$, respectively) estimated from the XRD patterns are listed together with the $\mathrm{F} / \mathrm{C}$ atomic ratios in Table 1. In this table, "X(hk(l))" $\left(X=I_{c}, a, L_{c}\right.$ and $\left.L_{a}\right)$ means the parameter $X$ determined by the $(h k(l))$ diffraction peak. The displacement of the $(h k)$ diffraction peaks toward larger $2 \theta$ associated with small coherent lengths [11] has been taken into account in determination of $a(h k)$. Precise determination of the $a$-lattice parameters based on the $(h k)$ diffraction peaks seems to be quite difficult. The values $a(10)$ and $a(11)$ estimated for F-1 disagree with each other. The $a(10)$ determined for F-2 slightly differ from that of F-3 although both of these samples are $(\mathrm{CF})_{n}$. The $\left(\mathrm{C}_{2} \mathrm{~F}\right)_{n}$ samples actually contain small $(\mathrm{CF})_{n}$-like domains in addition to trace of peripheral $>\mathrm{CF}_{2}$ groups on the surface, as is suggested by the F/C ratios of larger than stoichiometric value of the compound, 0.50 [7]. However, such domains in the sample F-1 are too small and dispersed to be detected by 
XRD. A smaller $I_{c}$ and larger crystallite sizes observed for the sample F-2 indicate a higher crystallinity than that of F-3. The F/C ratios of larger than 1.0 determined for these $(\mathrm{CF})_{n}$ samples suggest the existence of considerable amount of the peripheral $>\mathrm{CF}_{2}$ groups in these fluorides, which have been characterized by ${ }^{19} \mathrm{~F}$ and ${ }^{13} \mathrm{C} \mathrm{NMR}$ spectroscopy [16]. The weighting factors $w_{i-j}$ of F-1, F-2 and F-3 are derived from the $\mathrm{F} / \mathrm{C}$ ratios listed in Table 1 according to Eq. (7) (Table 2).

$S(Q)$ 's of the layered carbon fluorides, graphite and PTFE derived from neutron diffraction data are shown in Fig. 3. In the $S(Q)$ 's of the layered carbon fluorides, small angle scattering intensities are strong at lower $Q$ than that of the (001) Bragg diffraction peaks. The prominent peak found at around $13 \mathrm{~nm}^{-1}$ (corresponding to the $d$ value of about $0.48 \mathrm{~nm})$ in the $S(Q)$ of PTFE is ascribed to the correlation between the $\left(\mathrm{CF}_{2}\right)_{n}$ chains [10]. The $R D F(r)$ 's derived from these $S(Q)$ 's by Eq. (3) are shown in Fig. 4. The $R D F(r)$ 's of the layered carbon fluorides with covalent $\mathrm{C}-\mathrm{F}$ bonds and puckered sheets of $\mathrm{sp}^{3}$-hybridized carbon atoms are completely different from that of the original graphite. The peaks found in the $R D F(r)$ of F-3 are poorly resolved compared to that for F-2, which is considered to be caused by the difference in the crystallinity between these $(\mathrm{CF})_{n}$ samples. The prominent peak found at $r$ of around $0.24 \mathrm{~nm}$ in the $R D F(r)$ of PTFE is ascribed to the correlations of the second nearest atomic pairs such as $\underline{\mathrm{F}}-\mathrm{C}-\underline{\mathrm{F}}$ and $\underline{\mathrm{C}}-\mathrm{C}-\underline{\mathrm{F}}$. The $R D F(r)$ profile of each fluoride at $r$ from 0.1 to $0.2 \mathrm{~nm}$ is separated to two Gaussian peaks corresponding to the pair correlations for $\mathrm{C}-\mathrm{F}$ and $\mathrm{C}-\mathrm{C}$ as shown in Fig. 5. $C N_{\mathrm{C}-\mathrm{F}}$ and $C N_{\mathrm{C}-\mathrm{C}}$ derived from the peak areas according to Eq. (8) are listed in Table 3, together with $r_{\mathrm{C}-\mathrm{F}}$ and $r_{\mathrm{C}-\mathrm{C}}$ determined by the peak positions. $C N_{\mathrm{C}-\mathrm{F}}$ obtained for the four samples are close to their $\mathrm{F} / \mathrm{C}$ atomic ratios. The sums $C N_{\mathrm{C}-\mathrm{F}}+C N_{\mathrm{C}-\mathrm{C}}$ obtained for F-1, F-3 and PTFE agree with the ideal value of an $\mathrm{sp}^{3}$-hybridized carbon 
atom, 4.00, while that of F-2 is a little larger due to the overestimated $C N_{\mathrm{C}-\mathrm{C}}$. The $r_{\mathrm{C}-\mathrm{F}}$ and $r_{\mathrm{C}-\mathrm{C}}$ in $(\mathrm{CF})_{n}$ almost coincide with those in $\left(\mathrm{C}_{2} \mathrm{~F}\right)_{n}$, also agreeing with those found for PTFE [10]. They are close to the estimated values based on the density functional theory $\left(r_{\mathrm{C}-\mathrm{F}}=0.137 \mathrm{~nm}, r_{\mathrm{C}-\mathrm{C}}=0.155 \mathrm{~nm}\right)$ [9] rather than to those estimated from the typical covalent radii of carbon and fluorine atoms $\left(r_{\mathrm{C}-\mathrm{F}}=0.141 \mathrm{~nm}, r_{\mathrm{C}-\mathrm{C}}=0.153-0.154\right.$ $\mathrm{nm})[5,6]$.

3.2 Refinement of the structure models of $\left(C_{2} F\right)_{n}$ and $(C F)_{n}$

The structure parameters such as the $a$-lattice parameters, atomic coordinates and thermal factors in the proposed structure models of $\left(\mathrm{C}_{2} \mathrm{~F}\right)_{n}$ and $(\mathrm{CF})_{n}$ were refined so as to give the best fit of $G_{\text {calc }}(r)$ 's to $G_{\text {obs }}(r)$ 's of the samples F-1, F-2 and F-3. The parameters $I_{c}, r_{\mathrm{C}-\mathrm{F}}$ and $r_{\mathrm{C}-\mathrm{C}}$ were fixed as they have been determined in Section 3.1, and the space symmetry of the monolayers $\left(P \overline{3} m 1\right.$ for AB-type $\left(\mathrm{C}_{2} \mathrm{~F}\right)_{n}$ and $(\mathrm{CF})_{n}, \quad P \overline{6} m 2$ for AA'-type $\left(\mathrm{C}_{2} \mathrm{~F}\right)_{n}[6,8]$. See Fig. 6) were maintained during the refinement. Two types of the ordered stacking sequences were assumed here to simplify the calculation of $G_{\text {calc }}(r)$ 's, while the samples F-1, F-2 and F-3 actually possess randomly stacked layers. The type-I and type-II stacking sequences make the nearest pair of fluorine atoms on the adjacent layers take the maximum and minimum distances, respectively (Fig. 7).

$G_{\text {calc }}(r)$ 's based on the four types of the structure models for $\left(\mathrm{C}_{2} \mathrm{~F}\right)_{n}$ (a-I, a-II, b-I and b-II in Fig. 7) are shown in Fig. 8, compared to $G_{\text {obs }}(r)$ of F-1. The $R$ values of the refinement at $r$ from 0.1 to $0.8 \mathrm{~nm}$ are $17.4,21.1,34.8$ and $25.4 \%$ for $G_{\text {calc }}(r)$ 's based on the models of a-I, a-II, b-I and b-II, respectively. Since the contribution of the 
interlayer correlations to $G(r)$ at $r$ below $0.5 \mathrm{~nm}$ is much less than that of the intralayer correlations, the profiles of $G_{\text {calc }}(r)$ 's at such $r$ range do not strongly depend on the type of the stacking sequences of the monolayers. On the other hand, relative intensities of the peaks found at $r$ of $0.3-0.4 \mathrm{~nm}$ in $G_{\text {calc }}(r)$ 's based on the AB-type models (a-I and a-II) clearly differ from those for AA'-type models (b-I and b-II), which is caused by the different forms of $\mathrm{C}_{6}$ rings in the unit cells ("chair" and "boat" forms for the former and the latter models, respectively. See Fig. 6). $G_{\text {calc }}(r)$ 's of AB-type models better fit to $G_{\text {obs }}(r)$ than those of AA'-type models, therefore it is concluded that the former type is more reasonable for the monolayer structure of $\left(\mathrm{C}_{2} \mathrm{~F}\right)_{n}$.

The $G_{\text {calc }}(r)$ 's based on the structure models of $(\mathrm{CF})_{n}$ with type-I and type-II stacking sequences (c-I and c-II in Fig. 7, respectively) are fitted to the $G_{\text {obs }}(r)$ 's of F-2 and F-3 in Fig. 9. The $R$ values on the pairs of $\left(G_{\text {obs }}(r), G_{\text {calc }}(r)\right)$ at $r$ from 0.1 to $0.6 \mathrm{~nm}$ are 25.8, 24.6, 32.2 and $34.8 \%$ for $(\mathrm{F}-2, \mathrm{c}-\mathrm{I}),(\mathrm{F}-2, \mathrm{c}-\mathrm{II}),(\mathrm{F}-3, \mathrm{c}-\mathrm{I})$ and $(\mathrm{F}-3, \mathrm{c}-\mathrm{II})$, respectively. The larger $R$ values obtained for F-3 than those for F-2 seem to be mainly caused by the larger discrepancy of $G_{\text {calc }}(r)$ 's from $G_{\text {obs }}(r)$ at $r$ of around $0.24 \mathrm{~nm}$. Since the structural defects in $(\mathrm{CF})_{n}$ such as $>\mathrm{CF}_{2}$ groups are not taken into account for the calculation of $G_{\text {calc }}(r)$ 's, the residual components given by $G_{\mathrm{obs}}(r)-G_{\mathrm{calc}}(r)$ at such $r$ are reasonably ascribed to the correlations of the second nearest atomic pairs such as $\underline{\mathrm{F}}-\mathrm{C}-\underline{\mathrm{F}}$ and $\underline{\mathrm{C}}-\mathrm{C}-\underline{\mathrm{F}}$ involving $>\mathrm{CF}_{2}$ groups. These results indicate that $\mathrm{F}-3$ contains a larger amount of $>\mathrm{CF}_{2}$ groups than those in F-2, which is in accordance with the lower crystallinity of the former described in Section 3.1. At $r$ out of around $0.24 \mathrm{~nm}, G_{\mathrm{obs}}(r)$ of F-3 as well as that of F-2 is well simulated by $G_{\text {calc }}(r)$ 's.

The structure parameters of the refined monolayeres of $\left(\mathrm{C}_{2} \mathrm{~F}\right)_{n}$ and $(\mathrm{CF})_{n}$ based on $G_{\text {obs }}(r)$ 's of F-1, F-2 and F-3 are listed in Table 4. For each sample, the assumed type 
of the stacking sequences does not strongly affect the refined parameters. The parameters refined for F-2 and that for F-3 agree well with each other, almost independent of the crystallinity of these $(\mathrm{CF})_{n}$ samples with different $I_{c}$. The $\angle \mathrm{F}-\mathrm{C}-\mathrm{C}$ and $\angle \mathrm{C}-\mathrm{C}-\mathrm{C}$ in $(\mathrm{CF})_{n}$ determined here agree with those calculated based on density functional theory $\left(108.2^{\circ}\right.$ and $110.7^{\circ}$, respectively) [9]. The $\angle \mathrm{C}-\mathrm{C}-\mathrm{C}$ as well as the $a$-lattice parameters determined for $(\mathrm{CF})_{n}$ are a little larger than those of $\left(\mathrm{C}_{2} \mathrm{~F}\right)_{n}$. Each carbon atom on the two-dimensional network of $\mathrm{C}-\mathrm{C}$ bonds in $(\mathrm{CF})_{n}$ is slightly displaced from the regular tetrahedral site with $\angle \mathrm{C}-\mathrm{C}-\mathrm{C}$ of $109^{\circ} 28^{\prime}$, due to the repulsive interaction between the nearest pair of fluorine atoms, but such distortion is less likely to occur in the diamond-like rigid network of $\mathrm{C}-\mathrm{C}$ bonds in $\left(\mathrm{C}_{2} \mathrm{~F}\right)_{n}$.

\section{Conclusion}

The $r_{\mathrm{C}-\mathrm{C}}$ 's in $\left(\mathrm{C}_{2} \mathrm{~F}\right)_{n}$ and $(\mathrm{CF})_{n}$ were determined to be 0.157 and $0.158 \mathrm{~nm}$, respectively, from the $R D F(r)$ 's obtained by neutron diffraction experiments, while the $r_{\mathrm{C}-\mathrm{F}}$ 's of both the compounds were estimated at $0.136 \mathrm{~nm}$. These bond lengths clearly indicate that the $\mathrm{C}-\mathrm{C}$ and $\mathrm{C}-\mathrm{F}$ bond characters in $\left(\mathrm{C}_{2} \mathrm{~F}\right)_{n}$ and $(\mathrm{CF})_{n}$ are essentially the same as those in PTFE. $G_{\text {calc }}(r)$ 's based on AB-type $\left(\mathrm{C}_{2} \mathrm{~F}\right)_{n}$ model better fit to $G_{\text {obs }}(r)$ of the compound than those of AA'-type model, therefore the latter is ruled out. The $a$-lattice parameter and $\angle \mathrm{C}-\mathrm{C}-\mathrm{C}$ determined for $(\mathrm{CF})_{n}\left(0.260-0.261 \mathrm{~nm}\right.$ and $111^{\circ}$, respectively) are a little larger than those for $\left(\mathrm{C}_{2} \mathrm{~F}\right)_{n}\left(0.256-0.257 \mathrm{~nm}\right.$ and $109-110^{\circ}$, respectively). The carbon network of $(\mathrm{CF})_{n}$ is more flexible than those in $\left(\mathrm{C}_{2} \mathrm{~F}\right)_{n}$ and slightly compressed so that the repulsion between the nearest pair of fluorine atoms 
attached on the sheet are decreased.

\section{Acknowledgement}

Dr. Shinji Kohara of Japan Synchrotron Radiation Research Institute is acknowledged for his valuable advices. A part of this work was financially supported by Kyoto University $21^{\text {st }}$ Century COE Program "Establishment of COE on Sustainable Energy System.”

\section{References}

[1] Watanabe N, Nakajima T, Touhara H. Graphite Fluorides, Amsterdam: Elsevier; 1988.

[2] Watanabe N, Nakajima T. Graphite fluorides and carbon-fluorine compounds. Boca Raton: CRC Press; 1991.

[3] Rüdorff W, Rüdorff G. Tetrakohlenstoffmonofluorid, eine neue Graphit-FluorVerbindung. Chem Ber 1947;80(5):417-423.

[4] Lagow RJ, Badachhape RB, Wood JL, Margrave JL. Some new synthetic approaches to graphite-fluorine chemistry. J Chem Soc Dalton Trans 1974;:1268-1273.

[5] Takashima M, Watanabe N. Formation and structure of crystalline graphite fluoride. J Chem Soc Jpn 1975;(3):432-436 [in Japanese].

[6] Touhara H, Kadono K, Fujii Y, Watanabe N. On the structure of graphite fluoride. Z 
anorg allg Chem 1987;544:7-20.

[7] Kita Y, Watanabe N, Fujii Y. Chemical composition and crystal structure of graphite fluoride. J Am Chem Soc 1979;101:3832-3841.

[8] Fujimoto H. Structure analysis of graphite fluoride by the Rietveld method. Carbon 1997;35(8):1061-1065.

[9] Charlier JC, Gonze X, Michenaud JP. First-principles study of graphite monofluoride (CF) ${ }_{n}$. Phys Rev B 1993;47(24):16162-16168.

[10] Schwartz BR, Mitchell GR. A detailed single chain model for molten poly(tetrafluoroethylene) from a novel structure refinement technique on neutron scattering data. Polymer 1994;35(15):3139-3148.

[11] Warren BE. X-ray diffraction in random-layer lattices. Phys Rev 1941;59:693-698.

[12] Paalman HH, Pings CJ. Numerical evaluation of X-ray absorption factors for cylindrical samples and annular sample cells. J Appl Phys 1965;33:2635-2639.

[13] Blech IA, Averbach BL. Multiple scattering of neutron in vanadium and copper. Phys Rev 1965;137(4A):1113-1116.

[14] Faber TE, Ziman JM. A theory of the electrical properties of liquid metals. III. The resistivity of binary alloys. Phil Mag 1965;11(109):153-173.

[15] Proffen T, Billinge SJL. PDFFIT, a program for full profile structural refinement of the atomic pair distribution function. J Appl Cryst 1999;32(3):572-575.

[16] Krawietz TR, Haw JF. Characterization of poly(carbon monofluoride) by ${ }^{19} \mathrm{~F}$ and ${ }^{19} \mathrm{~F}$ to ${ }^{13} \mathrm{C}$ cross polarization MAS NMR spectroscopy. J Chem Soc Chem Commun $1998 ;: 2151-2152$. 
Table 1

Structure parameters of the samples F-1, F-2 and F-3

\begin{tabular}{llllllll}
\hline Sample & $\begin{array}{l}\text { Type of } \\
\text { fluoride }\end{array}$ & $\begin{array}{l}I_{c}(001) \\
(\mathrm{nm})\end{array}$ & $\begin{array}{l}a(10) \\
(\mathrm{nm})\end{array}$ & $\begin{array}{l}a(11) \\
(\mathrm{nm})\end{array}$ & $\begin{array}{l}L_{c}(001) \\
(\mathrm{nm})\end{array}$ & $\begin{array}{l}L_{a}(10) \\
(\mathrm{nm})\end{array}$ & $\mathrm{F} / \mathrm{C}$ ratio \\
\hline $\mathrm{F}-1$ & $\left(\mathrm{C}_{2} \mathrm{~F}\right)_{n}$ & 0.872 & 0.252 & 0.256 & 2.4 & 46 & 0.696 \\
$\mathrm{~F}-2$ & $(\mathrm{CF})_{n}$ & 0.623 & 0.258 & 0.258 & 6.1 & 58 & 1.190 \\
$\mathrm{~F}-3$ & $(\mathrm{CF})_{n}$ & 0.711 & 0.260 & $-{ }^{1)}$ & 2.4 & 28 & 1.184 \\
\hline
\end{tabular}

1) The (11) diffraction peak is too faint to determine $a(11)$. 
Table 2

Weighting factors $\left(w_{i-j}\right)$ of the samples F-1, F-2 and F-3 for neutron diffraction

\begin{tabular}{llll}
\hline Sample & $w_{\mathrm{C}-\mathrm{C}}$ & $w_{\mathrm{C}-\mathrm{F}}$ & $w_{\mathrm{F}-\mathrm{F}}$ \\
\hline $\mathrm{F}-1\left(\left(\mathrm{C}_{2} \mathrm{~F}\right)_{n}\right)$ & 0.395 & 0.467 & 0.138 \\
$\mathrm{~F}-2\left((\mathrm{CF})_{n}\right)$ & 0.247 & 0.500 & 0.253 \\
$\mathrm{~F}-3\left((\mathrm{CF})_{n}\right)$ & 0.249 & 0.500 & 0.251 \\
\hline
\end{tabular}


Table 3

Nearest neighbor coordination numbers $\left(C N_{i-j}\right)$ and interatomic distances $\left(r_{i-j}\right)$ of the fluoride samples

\begin{tabular}{llllll}
\hline Sample & $\begin{array}{l}C N_{\mathrm{C}-\mathrm{F}} \\
(\text { atoms })\end{array}$ & $\begin{array}{l}r_{\mathrm{C}-\mathrm{F}} \\
(\mathrm{nm})\end{array}$ & $\begin{array}{l}C N_{\mathrm{C}-\mathrm{C}} \\
(\text { atoms })\end{array}$ & $\begin{array}{l}r_{\mathrm{C}-\mathrm{C}} \\
(\mathrm{nm})\end{array}$ & $\begin{array}{l}C N_{\mathrm{C}-\mathrm{F}}+C N_{\mathrm{C}-\mathrm{C}} \\
\text { (atoms) }\end{array}$ \\
\hline $\mathrm{F}-1\left[\left(\mathrm{C}_{2} \mathrm{~F}\right)_{n}\right]$ & 0.68 & 0.136 & 3.27 & 0.157 & 3.95 \\
$\mathrm{~F}-2\left[(\mathrm{CF})_{n}\right]$ & 1.05 & 0.136 & 3.22 & 0.158 & 4.27 \\
$\mathrm{~F}-3\left[(\mathrm{CF})_{n}\right]$ & 1.12 & 0.136 & 2.89 & 0.158 & 4.01 \\
$\mathrm{PTFE}$ & 1.98 & 0.135 & 1.97 & 0.157 & 3.95 \\
& & $(0.136[10])$ & & $(0.158[10])$ \\
\hline
\end{tabular}


Table 4

The structure parameters for the refined models of the monolayers in $\left(\mathrm{C}_{2} \mathrm{~F}\right)_{n}$ and $(\mathrm{CF})_{n}$

\begin{tabular}{lllllll}
\hline Sample $\left(I_{c} / \mathrm{nm}\right)$ & \multicolumn{2}{l}{ F-1 $(0.872)$} & \multicolumn{2}{l}{ F-2 $(0.623)$} & \multicolumn{2}{l}{ F-3 $(0.711)$} \\
\hline $\begin{array}{l}\text { Assumed stacking } \\
\text { sequence }\end{array}$ & a-I & a-II & c-I & c-II & c-I & c-II \\
$a / \mathrm{nm}$ & & & & & & \\
$I_{c} z_{1}\left(\mathrm{C}_{1}\right)^{1)} / \mathrm{nm}$ & 0.257 & 0.256 & 0.260 & 0.261 & 0.260 & 0.260 \\
$I_{c} z_{2}\left(\mathrm{C}_{2}\right)^{1)} / \mathrm{nm}$ & 0.130 & 0.078 & 0.025 & 0.024 & 0.025 & 0.025 \\
$I_{c} z_{3}(\mathrm{~F})^{1)} / \mathrm{nm}$ & 0.266 & 0.268 & 0.161 & 0.160 & 0.161 & 0.161 \\
$\angle \mathrm{F}-\mathrm{C}-\mathrm{C} /{ }^{\circ}$ & 109 & 110 & 108 & 108 & 108 & 108 \\
$\angle \mathrm{C}-\mathrm{C}-\mathrm{C} /{ }^{\circ}$ & $110^{2)}$, & $109^{2)}$, & 111 & 111 & 111 & 111 \\
& $109^{3)}$ & $110^{3)}$ & & & & \\
\hline
\end{tabular}

1) Atomic coordinates of the atoms $\mathrm{C}_{1}, \mathrm{C}_{2}$ and $\mathrm{F}$ are given by $\left(\frac{1}{2} \pm \frac{1}{6}, \frac{1}{2} \mp \frac{1}{6}, \frac{1}{2} \pm z_{1}\right),(0$,

$\left.0, \frac{1}{2} \pm z_{2}\right)$ and $\left(\frac{1}{2} \pm \frac{1}{6}, \frac{1}{2} \mp \frac{1}{6}, \frac{1}{2} \pm z_{3}\right)$, respectively.

2) $\angle \mathrm{C}_{1}-\mathrm{C}_{2}-\mathrm{C}_{1},, \angle \mathrm{C}_{2}-\mathrm{C}_{1}-\mathrm{C}_{2}$,

3) $\angle \mathrm{C}_{2}-\mathrm{C}_{1}-\mathrm{C}_{1}$ ' 


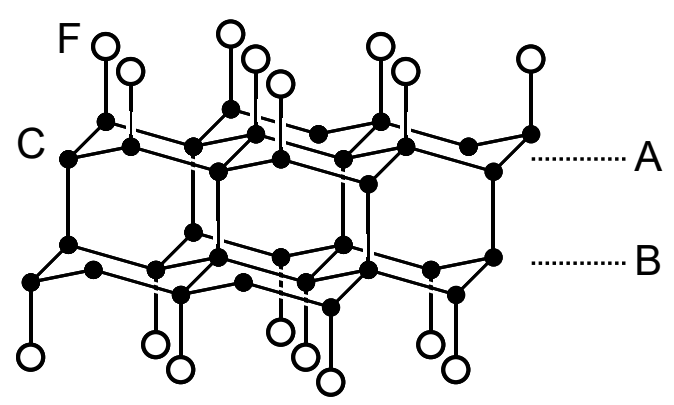

a: AB-type $\left(\mathrm{C}_{2} \mathrm{~F}\right)_{n}$

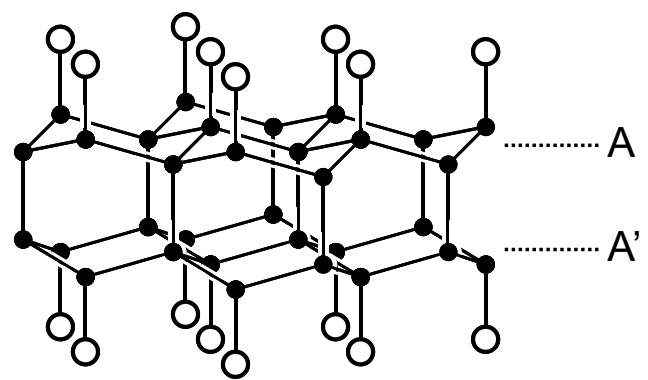

b: AA'-type $\left(\mathrm{C}_{2} \mathrm{~F}\right)_{n}$

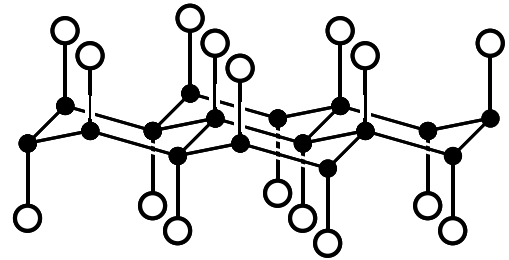

C: $(\mathrm{CF})_{n}$

Fig. 1. Proposed structural models of monolayers in (a) AB-type $\left(\mathrm{C}_{2} \mathrm{~F}\right)_{n}$, (b) AA'-type $\left(\mathrm{C}_{2} \mathrm{~F}\right)_{n}$ and $(\mathrm{c})(\mathrm{CF})_{n}$. 


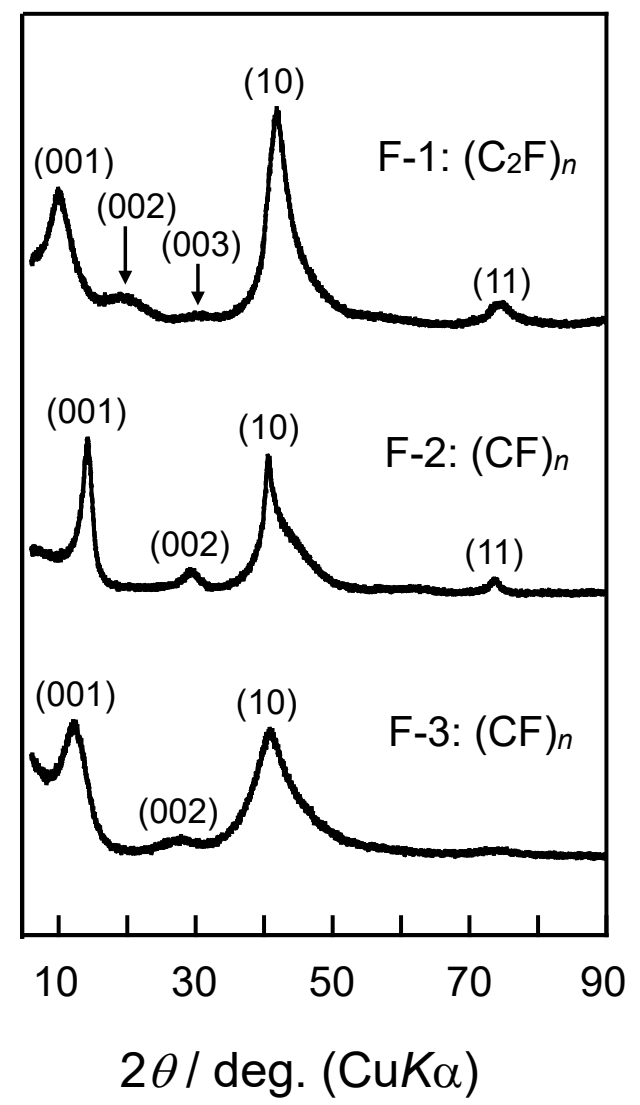

Fig. 2. XRD patterns of the samples F-1, F-2 and F-3. 


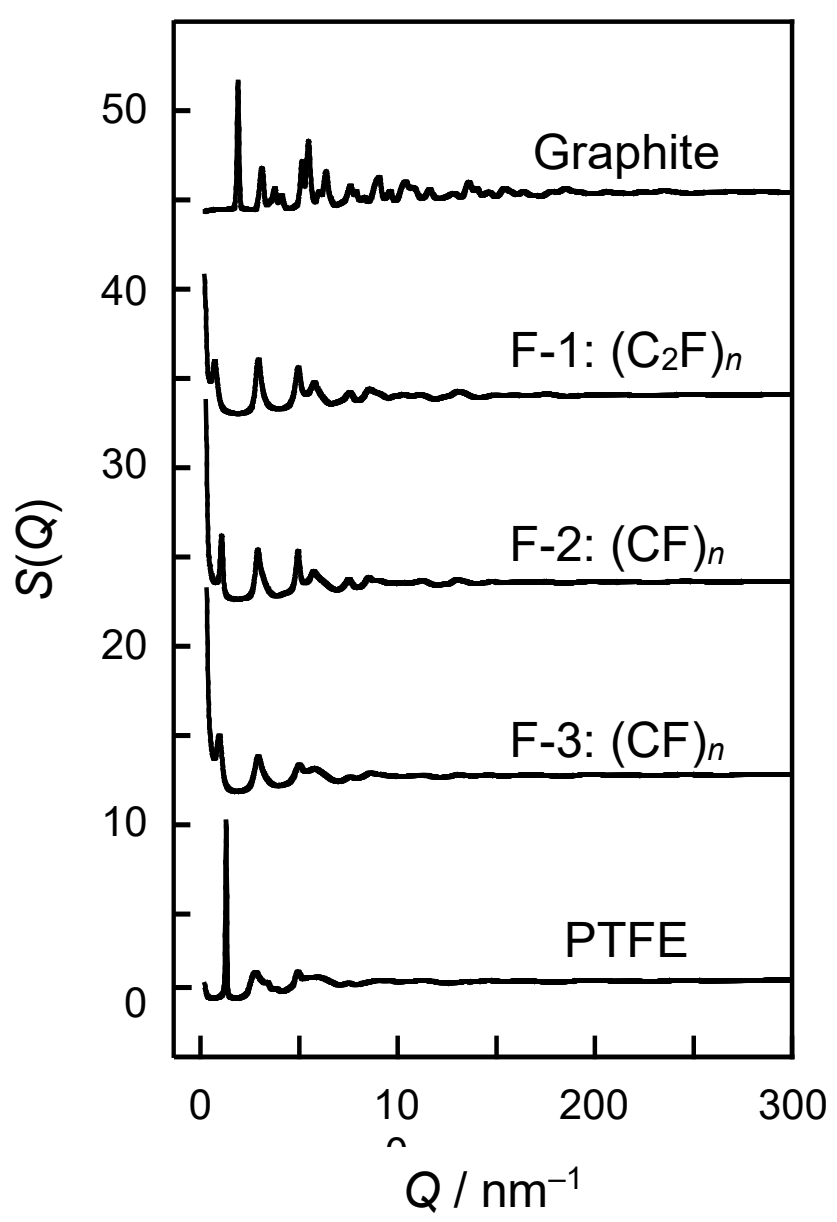

Fig. 3. The structure factors, $S(Q)$ 's, of graphite, the samples F-1, F-2, F-3 and PTFE derived from the neutron diffraction data. 


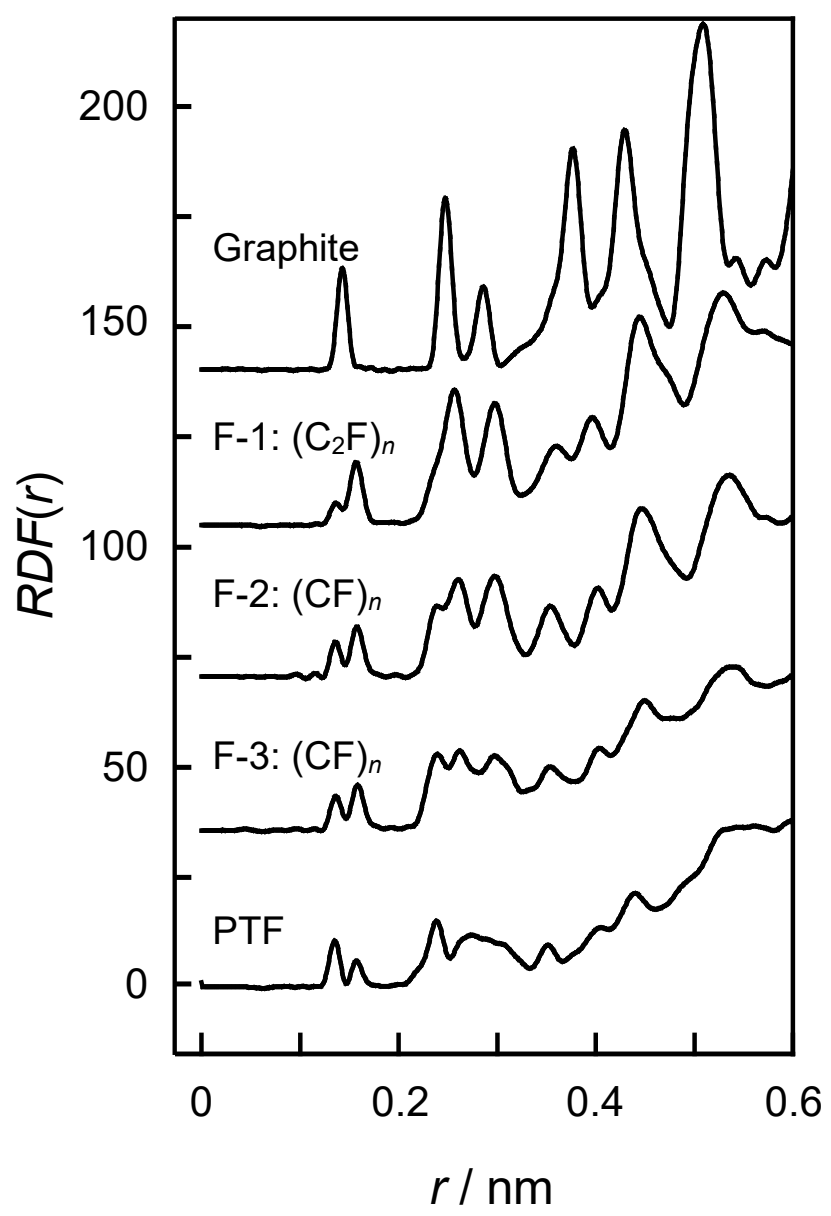

Fig. 4. Radial distribution functions, $R D F(r)$ 's, of graphite, the samples F-1, F-2, F-3 and PTFE. 


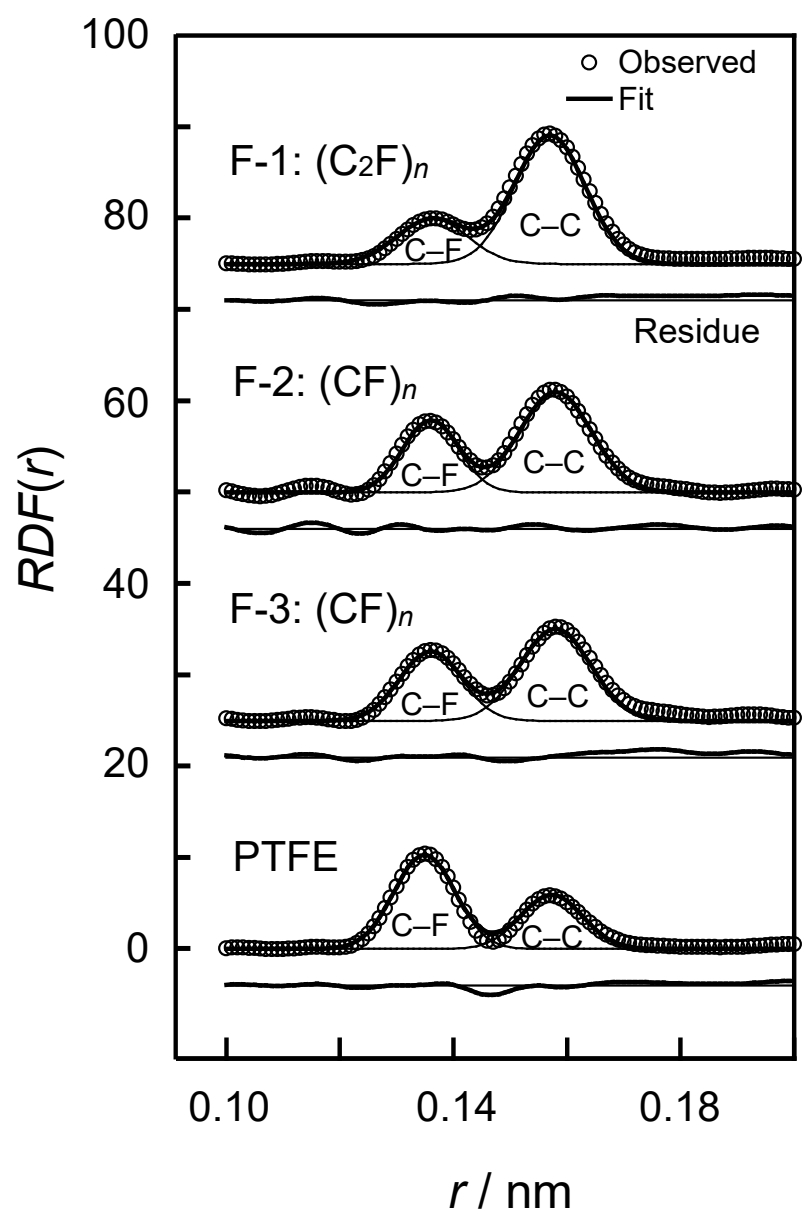

Fig. 5. Radial distribution functions, $R D F(r)$ 's, of the samples F-1, F-2, F-3 and PTFE. 

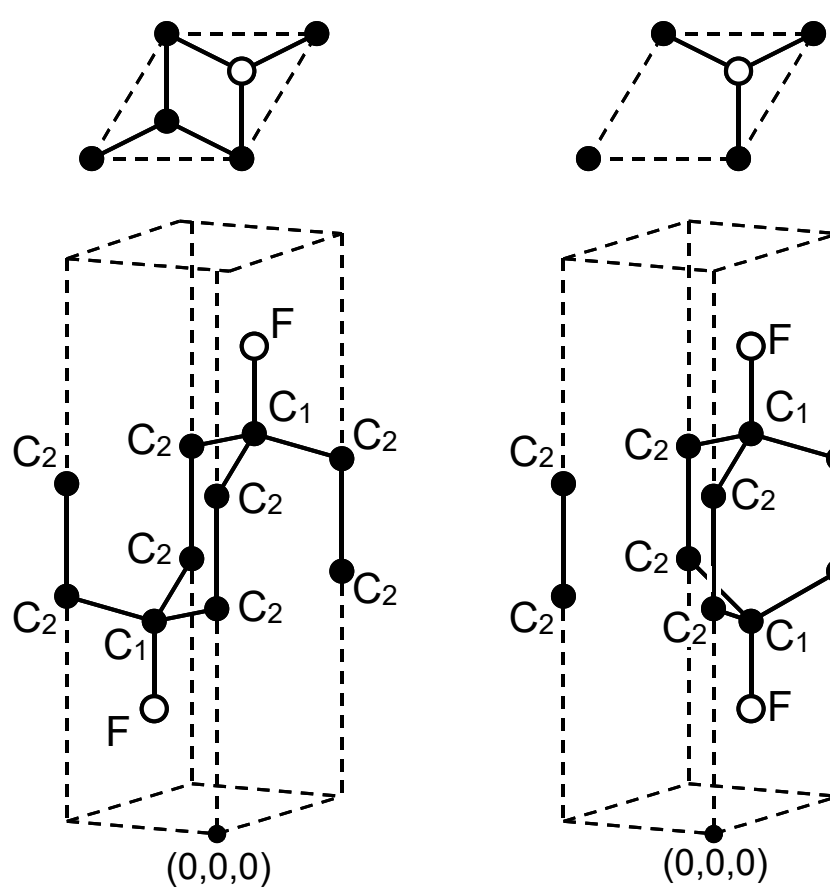

a: $\left(\mathrm{C}_{2} \mathrm{~F}\right)_{n}$

(AB-type)

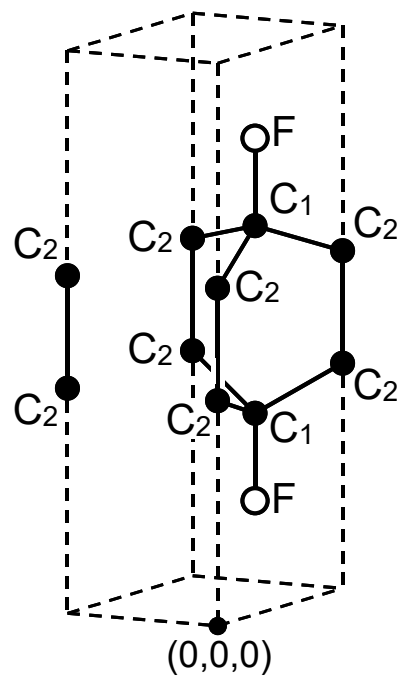

b: $\left(\mathrm{C}_{2} \mathrm{~F}\right)_{n}$

(AA'-type)
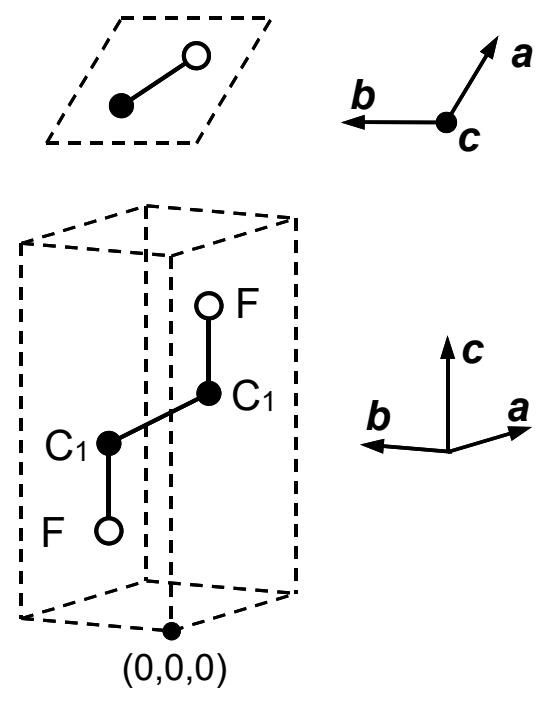

c: $(\mathrm{CF})_{n}$

Fig. 6. The unit cells of the monolayers of (a) AB-type $\left(\mathrm{C}_{2} \mathrm{~F}\right)_{n}$, (b) AA'-type $\left(\mathrm{C}_{2} \mathrm{~F}\right)_{n}$ and (c) $(\mathrm{CF})_{n}$. 


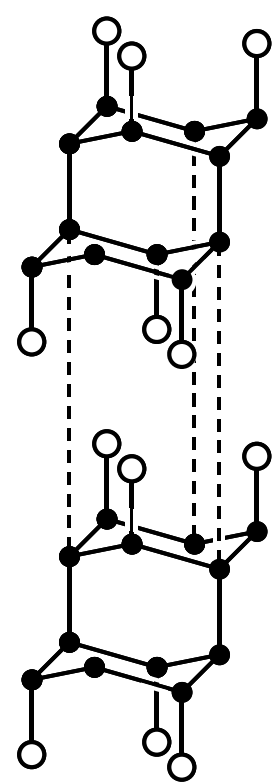

$$
\begin{gathered}
\text { a-I: }\left(\mathrm{C}_{2} \mathrm{~F}\right)_{n} \\
\text { AB-type } \\
\text { Stacking-I }
\end{gathered}
$$

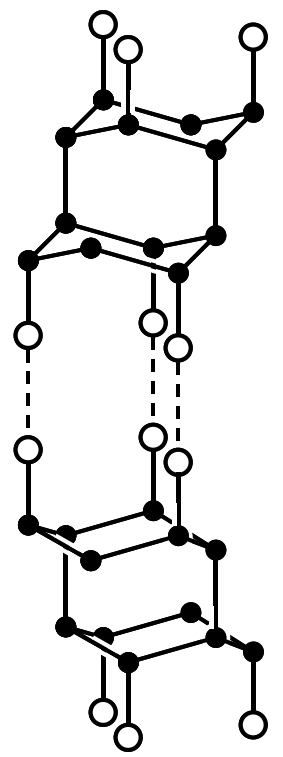

$$
\begin{gathered}
\text { a-II: }\left(\mathrm{C}_{2} \mathrm{~F}\right)_{n} \\
\text { AB-type } \\
\text { Stacking-II }
\end{gathered}
$$

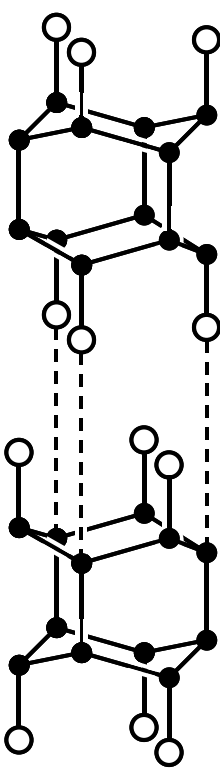

b-I: $\left(\mathrm{C}_{2} \mathrm{~F}\right)_{n}$

AA'-type

Stacking-I

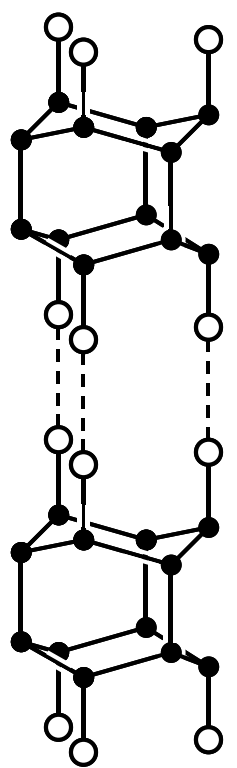

b-II: $\left(\mathrm{C}_{2} \mathrm{~F}\right)_{n}$

AA'-type

Stacking-II

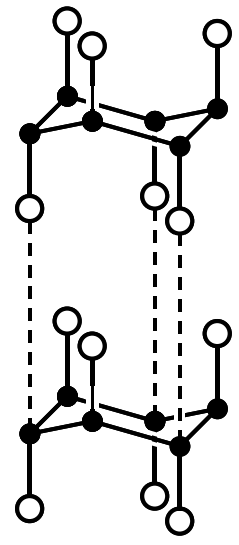

C-I: $(\mathrm{CF})_{n}$ Stacking-I

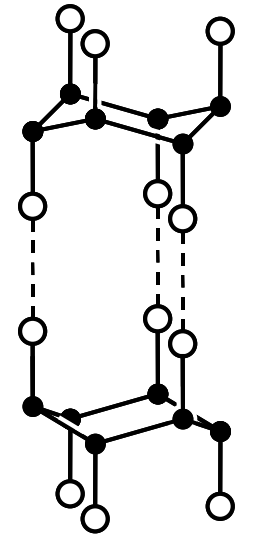

Fig. 7. The stacking sequences of the monolayers of AB-type $\left(\mathrm{C}_{2} \mathrm{~F}\right)_{n}$, AA'-type $\left(\mathrm{C}_{2} \mathrm{~F}\right)_{n}$ and $(\mathrm{CF})_{n}$ assumed for the $G(r)$-based refinement of the structure models. 


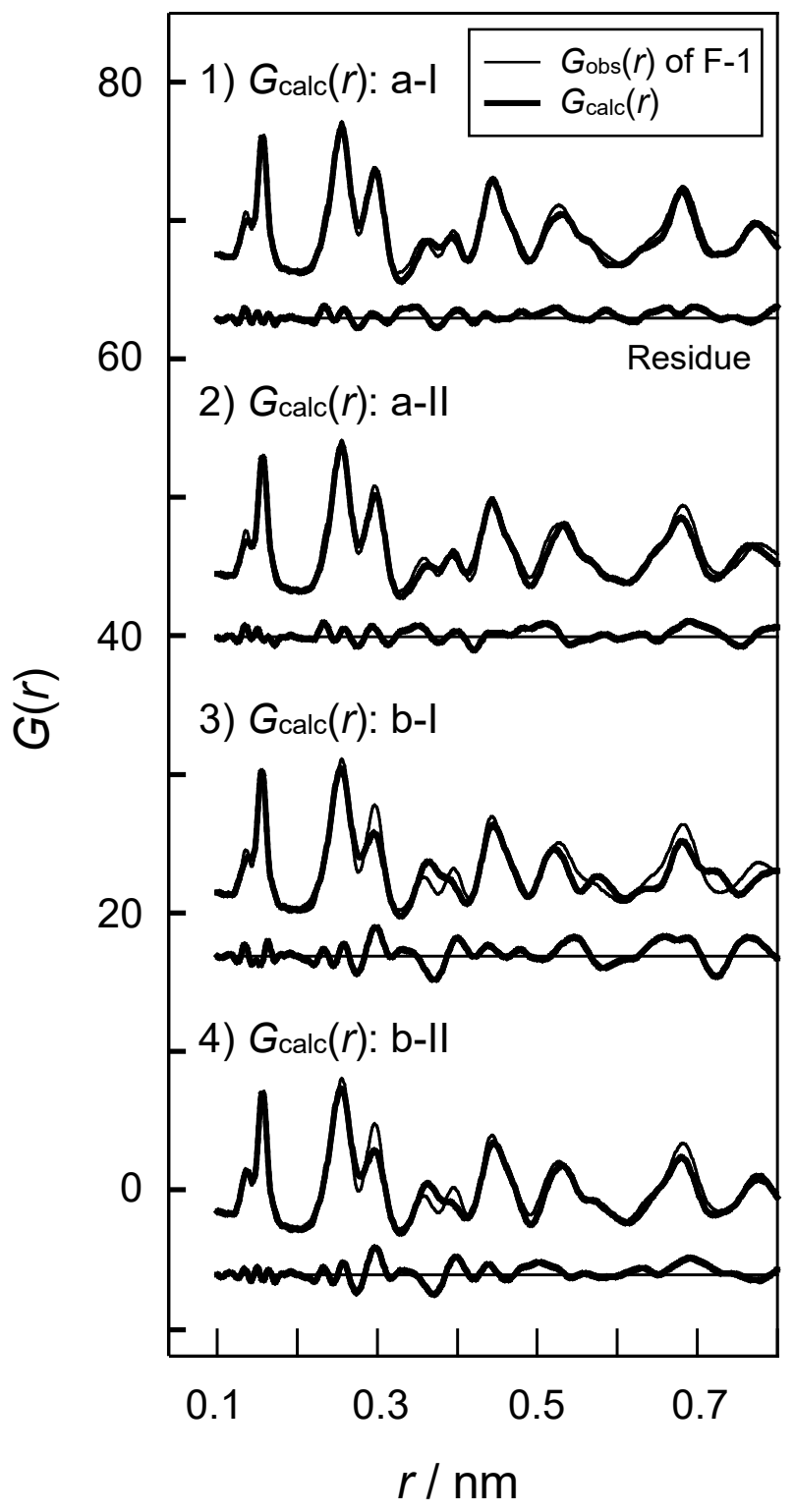

Fig. 8. Atomic pair distribution functions, $G(r)$ 's, of the $\left(\mathrm{C}_{2} \mathrm{~F}\right)_{n}$ structure models fitted to the curve experimentally obtained for the sample F-1. 


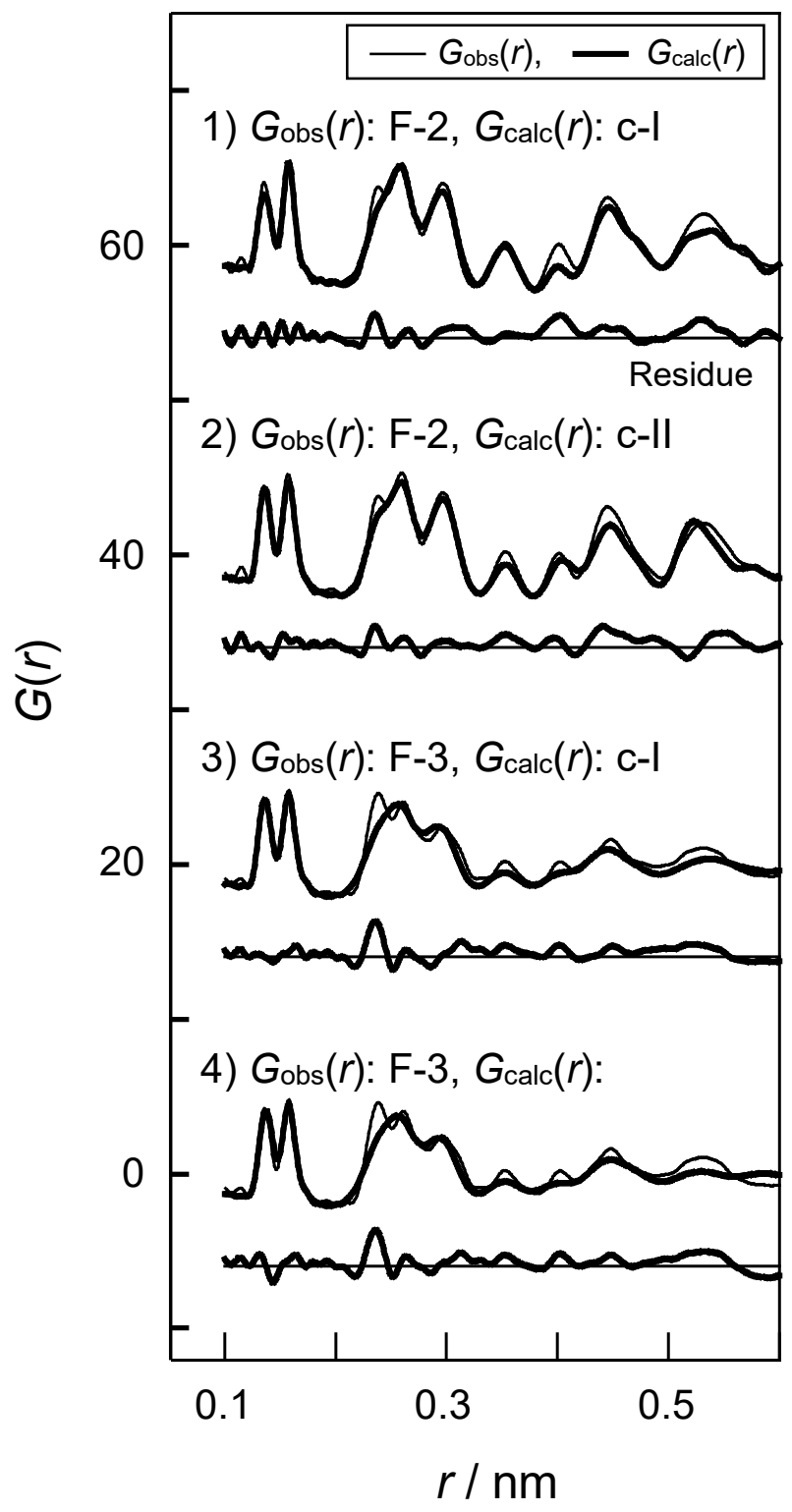

Fig. 9. Atomic pair distribution functions, $G(r)$ 's, of the $(\mathrm{CF})_{n}$ structure models fitted to the curves experimentally obtained for the samples F-2 and F-3. 